\title{
The Life Hazard in Crowded Buildings Due to Inadequate Exits*
}

\author{
Faults Exposed and Remedies Suggested
}

\author{
By H. F. J. Porter
}

Buildings in general are either non-fireproof or fireproof. The former can be compared to a pile of kindling wood out in the open, sometimes oil soaked and always ready to be set on fire. The latter are comparable to a stove full of fuel ready to be set on fire. In both cases the human occupants swarm around in the interstices in the pile of fuel, and as soon as the fire starts those caught in the fagots have to work their way down through the smoke and flames to the ground to save their lives.

Factory buildings in particular are sources of great danger to their large number of occupants, both on aceount of their non-fireproof construction and because of the obstructions to rapid egress, due to haphazard placing of machinery, furniture and partitions and the small number, size and character of these exit facilities.

Of late, there has been advocated the unrestricted use of fireproof construction in the buildings themselves and the author has recommended the development of a form of exit drill of the occupants of each building to determine if, in the case of danger, they could escape readily from the building and if they could not, the alteration of the exite until they could. By "reedily" is meant within three minutes, for from many conferences it was found that people do not want, nor would it be safe, to remain in a burning building longer than that time.

The capacity of a stairway, if time is not a factor and a stream of people pours into it only at the top and out of it from the bottom, is unlimited; but if time is to be congidered the capacity is limited by its cross-sectional area. In a multi-storied building with crowds of people on each floor trying at different points in its length to get on to one stairway in a limited time, the conditions are very different. If more people try to get on to the stairs from each floor than the section between that floor and the floor below will hold, a jam will occur so that the flow downward will cesse. The capacity of this section is very limited.

A crowd of people does not flow like a liquid composed of round smooth molecules. Their soft bodies are angular in shape more like pieces of rubber with wires in them and they therefore interlock. Clothes present rough surfaces causing friction and if the stairway is narrow an arch is apt to form across it which can become an obstruction in case of pressure from above such as actually o burst the stair rail or inclosing partition.

The capacity of a stairway of the average height of from 10 to 12 feet between floors and not less than 22 inches wide would be one person on every other step or 10 and 12 per floor respectively, and if the width is doubled (not less than 44 inches) so that two people can come down abreast, twice those numbers or 20 and 24. If a stairway has winders in it, its capacity is reduced 50 per cent Ope person can descend a single flight of such steps 10 to 12 feet high in 10 seconds, striking a gait which he can maintain for seven or eight flights of steps. After that he goes slower, making the tenth flights in about 11 or 12 seconds. Every person added in single file adds 1 second seconds. Every person added in single file adds 1 second to this time. A double file takes no longer if the stairs
are double width. Thus it will take 10 seconds for 10 or are double width. Thus it will take 10 seconds for 10 or
20 people, that is, the full capacity of a flight of steps, to come down one story. The capacity of a stairway may be thus increased by widening it in multiples of 22 inches. A crowd of people cannot be depended upon to come down more than ten stories. One or more of them will give out, and demand the attention of others. Those who do get down will be severely taxed. The total time required to empty a building is determined by the time required to empty a building is determined by the time ground or the floor occupied by the greatest number of people.

FORMOLA FOR EMPTYING A FLOOR BY ONE BTAIRWAY. Number of couples (number of people divided by 2)...c

Time of formation in line after signal, seconds.

- Paper read before The American Soclety of Mecbanical

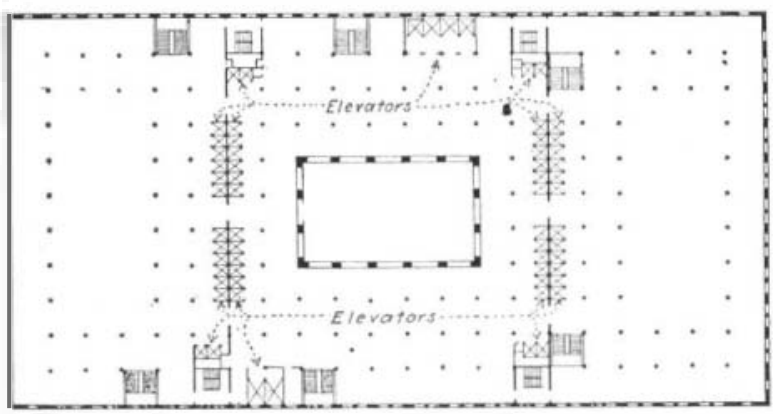

Fig. 2.-Department store floor plan showing present arrangement of fire walls, elevators and stairs.
Time one couple takes to march to top of stairs, seconds10 ime each couple takes to pass through door at top of stairs, seconds.

Number of stair flights (oneless than number of floors). $f$ Time of one couple to descend one flight of stairs, seconds........

Time of one couple to go from foot of stairs to street

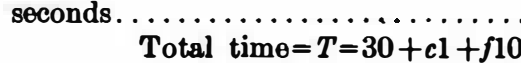

Example. Time of emptying 100 people from tenth

$T=30+50+90=170$ seconds $=2$ minutes, 50 seconds.

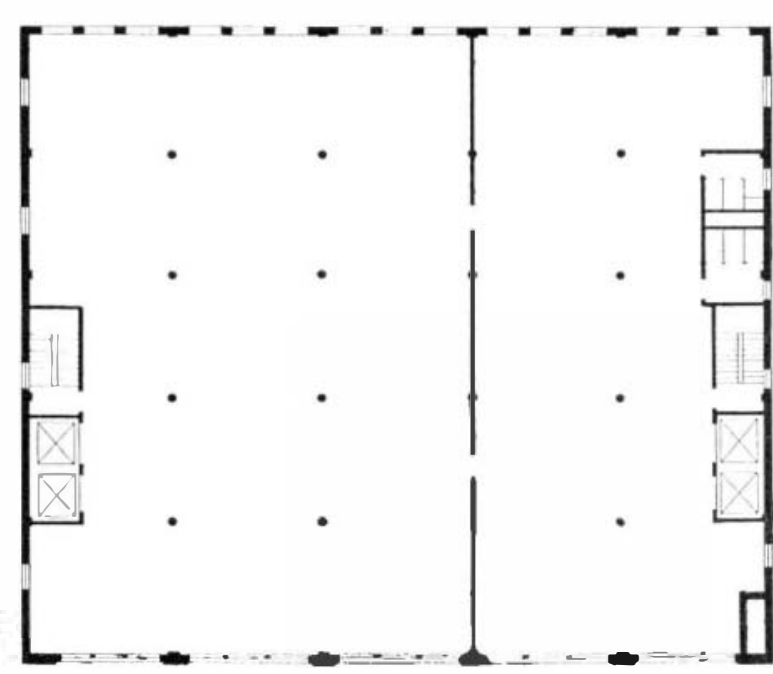

Fig. 1.-Floor plan of typical loft building showing fire wall with doorways.

Example.-Time of emptying a ten-story building with 20 people on each floor is the same as emptying 20 people rom tenth floor.

$T=30+10+90=130=2$ minutes, 10 seconds

Tests of the capacity of fire escapes in a limited time gave the following results: A straight ladder, 2 per floor; ladder set at 50 to 60 degrees with the horizontal requiring people to go down backwards 3 to 4 per floor; stair ing people to go down backwards 3 to 4 per foor; stairs
30 inches wide, 10 to 12 per floor; and the modern out30 inches wide, 10 to 12 per floor; and the modern out-
side stairway with a mezzanine platform 40 inches wide, 20 to 24 per floor, the same as an inside stairway. Fire
side stairway with a mezzanine platform 40 inches wide, escapes are usually so exposed to flames from windows opening upon them that they are more of ten fire traps than fire escapes. They should be prohibited by law and safer methods of escape provided.

In order to insure the safety of the occupants of a building in case of emergency one of two things has to be done: (a) there should be two stairways so that if one is cut off by flames or smoke the other can be used and the number of occupants reduced on each floor to meet the limited capacity of the part of the stairway between floors, or $(b)$ the number of stairways increased so as to have two separate and independent stairways from each floor to the ground with its own exit from the building. People can then pour into the top whichever one is not cut off by the fire and continue down and out at the bottom without colliding with those from any other floor. Fire drills installed under either of these conditions worked drills installed under either of these conditions worked
more or less satisfactorily, and the author tried unsucmore or less satisfactorily, and the author tried unsuc-
cessfully for years to have ordinances passed in New York city and legislation enacted at Albany, making them mandatory, but the expense of changes in the buildings and the idea of having employees walk out of a factory while manufacturing operations were under way, upon the sounding of an unexpected signal, did not appeal to factory proprietors as practical. It required holocaust in New Jersey, Pennsylvania and New York finally to in New Jersey, Pennsylvania and New Y
bring about the legislation in those States.

bring about the legislation in those States.
As time passed, however, the author developed what As time passed, however, the author developed what
might be termed an exit test in factories which presented the opportunity and found to his astonishment that almost without exception, exit facilities adequate for handling the regular number of occupants under emergency conditions, were lacking.

This situation has probably developed with the rapid growth of industry where a factory building had been built to accommodate a certain number of people, and then, as the business grew, more people were accommo dated without realizing that each additional person dated without realizing that each additional person
became an increment of danger to all. $\mathrm{Or}$, if the danger became an increment of danger to all. Or, if the danger
was at all appreciated, some means of escape from windows was supplied which might be any thing from a rope to a ladder. After this condition had become general it crystallized into custom, and new buildings with exit facilities inadequate for their occupancy were designed, erected and accepted as safe. Ropes were followed by ladders, and these in turn by fire escapes which became in time an established necessity.

Engineers, when called upon to supply a mechanism, are expected to have it subjected to a working test, which it must pass before they get paid for it; but architects and builders have never been called upon to demonstrate by actual test that the facilities which they have supplied in their buildings for the purpose of emptying them under emergency conditions will actually work, and this notwithstanding repeated instances of panic congestion on stairs, of people being burned to death on fire escapes, of elevators sticking from the warping of their runways from heat, etc.

When subjected to test these exit facilities in many buildings have been found to be entirely wanting in adequacy, and when this fact was brought to the attention of those who were responsible, it has been surprising to find how readily they accepted the eriticism. On the other hand, those who possess these unemptiable buildother hand, those who possess these unemptiable build-
ings are skeptical of such statements and unwilling to be ings are skeptical of such statements and unwilling to be
persuaded that the buildings are not safe. They point to all the other buildings erected by reputable architects and builders and naturally are incredulous.

In order to empty these buildings, additional stairways had to be built and fire drills developed to take the people out. Such changes in the building are expensive, for two stairways have to be installed from each floor to ground, so that if one is cut off by a fire, the other can be used. In many-storied buildings the number of stairways required becomes impractical. In addition fire drills are expensive to operate, for they involve not only loss of time of operatives and a break in the continuity of the process of manufacture, but the actual going down stairs and return of people, some of whom may be lame, others affected by weak hearts or lungs, others anaemic or organically weak, reduce the efficiency of the working foree for a very appreciable time. If the drill takes place at the end of the day this criticism might be modified slightly.

Such is the situation in the usual type of factory building to be found in the average town where ground is cheap, buildings large and stairways broad. Turning now to the loft building used for factory purposes, the conditions as regards emptiability are found to be very much worse and have to be corrected in a different manner. Let us consider for the moment a one-story or groundfloor factory building with a doorway at each side, one of which is cut off by a fire. The people can march out horizontally through the other doorway and nothing will impede this horizontal exit except the size of the doorway. If this is 22 inches wide, a single file of people can pass out in an orderly manner at the rate of one person every second. If it is 44 inches wide, a line of people two abreast can pass out in the same time. One hundred people can make their exit through one 44-inch door, therefore, in 50 seconds, or say one minute.

Now put another factory on top of this one with one hundred people in it. The doorway at each side will have to open on stairways which lead down to the doorways constituting the exits from the factory below. Suppose fire occurs on the floor below, cutting off one of these exits, the 100 people on the lower floor immediately proceed to make their horizontal exit, while those on the upper floor proceed to make a vertical downward exit to upper to proced to mo The the do is of cours a colligion, the slreare of poplo from upstairs coming down upon the stream of people on the ground floor on their way out. This collision prevent both the up-stairs stream from coming down and th down-stairs stream from going out. There is a complete lock, and the building does not empty.

Not only have we put one factory on another in the case of our loft building, but we have piled factory on

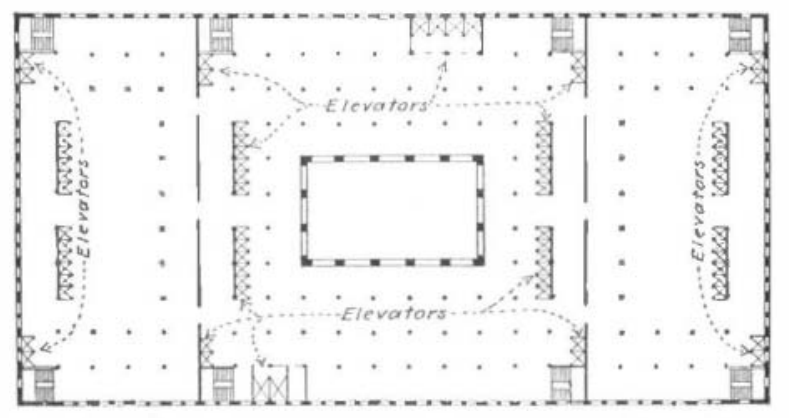

Fig. 3.-Suggested arrangement of fire walls, elevators and stairs for department store. 
factory until we have from 10 to 30 and more, one on top of the other; and each employing from 100 to 300 or more people. In cases of emergency as in the Asch Building fire, there are only two courses for the occupants: one is to burn to death, and the other to jump to death"to burn up or jump down."

It is impossible to reduce the number of people per floor to the capacity of the stairs, say 24 per floor. Even if that number were all that a business required, in case of emergency they would have to go down stairs, and it is a physical impossibility for people to stand the exertion a physical impossibility for people to stand the exertion
of a trip down more than ten stories without resting; and when they stop to rest they block the stream and obstruct its exit. Under these circumstances it is necessary to develop some other method for people in high building to secure safety. The following suggestion is offered to meet the situation:

It has been seen that a horizontal escape by people on the ground floor is readily secured. Let us see if a horizontal escape to safety for people at any height from the ground can be developed. Suppose a wall is built across the building from cellar to roof practically bisecting it in a way so as to have a stairway and elevator on each side. This wall should bave at least two doorways in it at a closing fireproof doors (Fig. 1)

It is improbable that a fire will occur on both sides of this wall simultaneously. It could occur only by incendiary origin, and that would hardly be possible in working hours. Should one occur on either side, the people on that side would go through the doorways in the fire wall, close the doors after them and be perfectly safe. That half of the-building in which the fire might be should be emptied in less than a minute if there were no more than 100 people on each floor to pass through one doorway 44 inches wide. If the principle of the horizontal escape presented by the fire wall is included in the design of new buildings a most satisfactory method of securing safety at comparatively small expense will be offered.

In every way possible the horizontal escape should be developed in old buildings and the vertical escape subordinated. Factory buildings adjoining one another may have doorways through their sides connecting them on various floors closed by fireproof self-closing doors, or may be connected by outside balconies built around the party walls; or, if of different heights, doors in the sides of one may lead out on the roofs of the others.

The fire wall bisecting the building as described makes practically two buildings, each provided with elevator practically two buildings, each provided with elevators
and stairways. A fire on one side of the wall would be and stairways. A fire on one side of the wall would be loss would be reduced one half. Only one half the people would be endangered and have to move, and the distance they would have to go would be only one half what it would be if they were on the ground floor of a building without a fire wall. They could remain on the same floo till the fire was extinguished, or could go down to the ground by the elevators operating under normal conditions.

The fire wall eliminates the necessity for a fire dril with its accompanying objections. Of course all building occupied by many people should have a fire alarm signal system in them to advise the people promptly of their danger. In buildings where there is a fire wall the signals should be arranged so that in case a fire should occur on one side of the fire wall on any floor, a bell on each floo on the same side of the fire wall would ring, indicating on which floor the fire is. Then all the people ing on which foor the fire is. Then all the people on that floor and above it should pass through the foors. Those below need not disturb themselves until the fire threatens them, and then they themselves until the fire threatens
too can pass through the fire wall.

too can pass through the fire wall.
There are certain other safety devices which should be supplied in factories to protect the lives of the operatives from fire. One of these is metal-framed windows with wire glass. These are made so as to close automatically in case of fire, thus preventing the latter from spreading upward from floor to floor outside of the building.

Another safety device is automatic sprinklers which Another safety device is automatic sprinklers which serve to extinguish fires in their incipiency. All doors
should be made to swing outward, and where they open on a hall or stair landing they should be vestibuled, so a not to obstruct the passage way. Sliding doors should be avoided if possible, as they are apt to stick or jam by pressure of people upon them.

Each floor of our typical loft buildings is, say, 100 feet by 100 feet by 10 feet and therefore contains 100,000 cubic feet of air. The laws of New York and many other states require 250 cubic feet of air per person as a limitation of occupancy. This limits the number of people per floor in a building of this size to 400 and if the stairway were 44 inches wide (and there are none now over 36 inches)at most only $\mathbf{4 0}$ per floor could possibly go down them even if the other 360 would let them.

With the fire wall only 200 of the 400 people on each floor would have to move, and if there were two doorways in the fire wall at some distance from each other, they could reach safety through them in one minute, or if one were cut off by the fire, all could pass through the other easily in two minutes. More doorways can be introduced, and thus the time of exit could be lowered still further. An effort is being made to increase the amount of air space required per person from 250 to 500 cubic feet, which would reduce the number of people per floor to 200 , of whom only 100 would have to move, and they could easily reach safety in one minute.

The stairways and elevators should be inclosed in fireproof walls to prevent a fire on one floor continuing upward and setting the other floors on fire. The ceiling of ward and setting the other floors on fire. The ceiling of
the basement where the machinery is located should be fireproof, and should not be pierced inside of the building, so that a fire there would not reach the elevator shafts.

Fire escapes which are simple stairs and possess dangerous features not only of limitations as to size, but of accessibility for flames and smoke, should be looked upon as evidence of the incompetence or innorance, or worse of the architect, builder, or owner, and prohibited by law under a heavy fine. They are not only dangerous to life by giving a false confidence in their adequacy for escape, but they destroy the appearance of the building. Our cities should be built without such architectural blemishes.

Fire escapes of the chute type are tubes with a smooth helix instead of steps. If the only opening is at the top they have considerable capacity. They soon rust, however, and at best are not to be considered seriously in ever, and at best are not to be considered seriously in comparison with other means of safe exit. People canis passing down from above.

The smoke-proof tower, claimed to have originated in Philadelphia, is the latest improvement in the line of fire escapes. It is simply an inclosed stairway on the outside of a building, but cannot be reached except by going out of doors. Its special claim is that smoke and flames cannot get into it. It has, however, no more capacity than any other stairway, and as its approach is always open to the weather and its interior is always more or less dark, it is never used in ordinary service and becomes neglected. These monuments to architectural incompetency can be seen here and there filled with the dust and accumulated rubbish of every unused open space. When a time arrives for using them everybody has forgotten their existence. During the last year or two, notwithstanding the protests of many, a great many new buildings have been constructed, especially in New York city, with these monstrosities on them, and have been accepted by the Building Department in all seriousness.

The fire wall should be introduced into all buildings where the public congregates in large numbers. Large department stores, which on certain days are said to accommodate several thousand people per floor, are very dangerous places at present. A fire, or a panic without a fire, might cause a fearful tragedy. It is criminal for their owners to object to fire walls and offer as an excuse that they would obstruct the vista. Certain cities require fire walls in such buildings now as a property protection, and the vista is dispensed with without comment. The department stores of Philadelphia are so divided; John Wanamaker's new store there is divided by two such walls as shown in Fig. 2. The exit facilities in it, however, are badly arranged, for the architect apparently did not think of the life hazard of its occupants, and designed the fire walls to protect property only. Fig. 3 shows how the building might be redesigned so as to be safer. It should be noted that the elevators are removed from the fire wall so that people trying to go down in them would not wall so that people trying to go down in them would not
block the doorways of the fire wall and prevent others coming through them. The stairways are situated as far from the fire wall as possible and should be inclosed by fire proof partitions.

Churches, assembly halls and similar ground-floo buildings should have their floor fireproof and unpierced so that any fire occurring in the basement would not endanger the occupants of the main building.

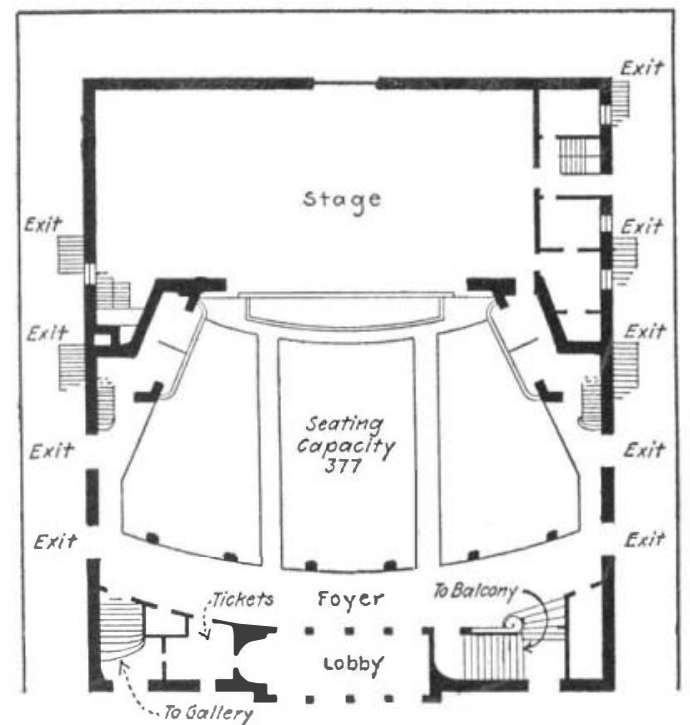

Fig. 4.-Typical and proposed theater plan showing use of fire walls, side entrances and exits.
Moving picture buildings, theaters, etc should be redesigned (Fig. 4). People come out of them by the way they go in, and in case of emergency all crowd into the narrow aisles. These aisles should be turned across the room and lead directly to courts opening on the street in a way such that streams of people will not collide. The various balconies and galleries should have foyer behind fire walls with separate stairs and street exits so that patrons will not have to mingle with those making the lower floor

Every school building should be divided by a fire wall providing a horizontal exit on each floor, so that the children will not have to be drilled to go down stairs in case of fire.

Hospitals where the inmates are bedridden, blind, lame nvalid, imbecile, or otherwise helpless, can be made safe by the introduction of the fire wall between wards, and in case of fire those who are bedridden can be wheeled on their beds through the doorways, and those who are up and about can walk through them.

Hotels and apartment buildings can so easily have fire wall developed in them that it need only be referred to here in passing. Even the private residence where only a few people oceupy a floor can be made safe in this way. The back stairway should be inclosed in a fireproof partition, and in case of a fire instead of everybody having to go down stairs through the smoke and flames, or having to jump from windows, the people on each floor have simply to pass through the fireproof door and go down stairs in safety. In large residences where there is a servants' quarters in connection with the back stairs, the building would be bisected and the people on either side of the wall would be able to carry their clothing and perhaps much household and personal property to safety.

\section{The Earth's Continental Pole}

M. Alphonge Berget, Professor at the Oceanographic Institute, has just made a series of very interesting pole of the earth.

If we take for the pole a little French island. the Isle of Dumet, situated near the mouth of the river Vilaine, we can trace a large circle, which divides the earth into two hemispheres in such a way that one contains almost the totality of continents, 45.5 per cent land and 54.5 per cent water; that is the Continental hemisphere, whereas the other, the Oceanic hemisphere, contains 88.7 per cent water and only 11.3 per cent of emerging land.

So, then, the Isle of Dumet, according to the successive trials and precise measurements of Prof. Berget, is the Continental pole of the earth. Any other point gives two hemispheres, of which the differentiation between terrestrial and marine domains is less marked.-Chemical News.

\section{A Rubens' Picture Identified by Photography}

Prof. Lippmann announced, a short while ago, that photography had been able to reproduce the traces that had become invisible to the naked eye, of retouchings made by Raphael on a certain number of his drawings.

By the use of a similar process, and by projecting a cone of ultra-violet rays on a picture attributed to Rubens, M. Parenty, Chief Engineer of the State Manufactories of Lille, has been able to identify the work of the great master.

This picture of the Museum of Lille is a decollation of St. John the Baptist, which was marked as attributed to Rubens. M. Parenty, on a photographic negative of this picture, has been able to show up very distinctly the authentic signature of the illustrious master. This signature having becomer completely invisible, had up till News.

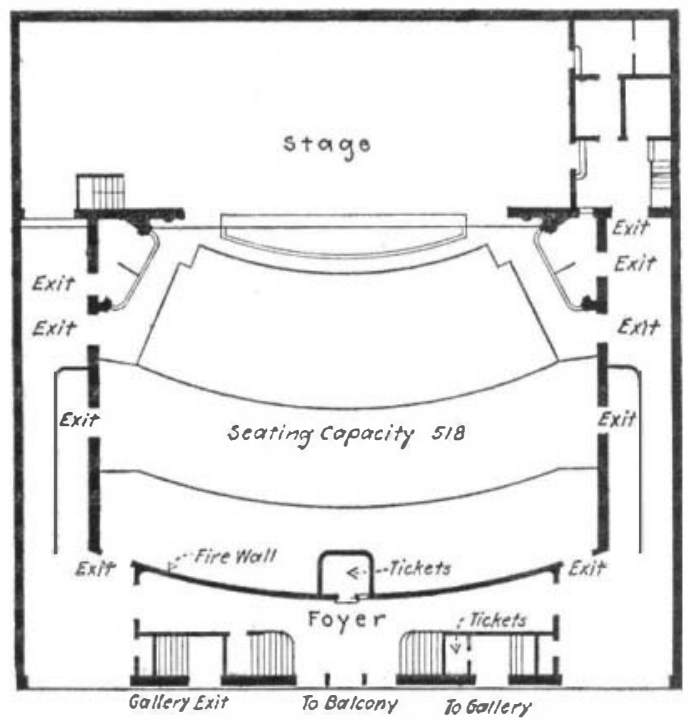

